\title{
Prevalence of pulmonary embolism at necropsy in patients with cancer
}

\author{
E SVENDSEN, B KARWINSKI
}

\author{
From the Department of Pathology, The Gade Institute, University of Bergen, Norway
}

SUMMARY The series studied comprised 6197 patients who had died of or who had cancer at death and represents all patients with cancer from 21530 necropsies performed at this department from 1960-84. Pulmonary embolism was significantly more common among cancer patients than in those with non-neoplastic diseases. Among those palliatively treated, patients with ovarian cancer, cancer of the extrahepatic bile duct system, and cancer of the stomach had the highest prevalence of pulmonary embolism $(34 \cdot 6 \%, 31 \cdot 7 \%$, and $15 \cdot 2 \%$, respectively). Necropsy patients with cancer of the oesophagus and larynx, together with leukaemia, myelomatosis, and malignant lymphoma had the lowest prevalence $(0-5 \cdot 6 \%)$. Palliatively treated cancers in organs of the peritoneal cavity had a significantly higher incidence than all other cancers combined. Cancer of the peritoneal cavity may impede venous drainage from the lower limbs and thus be an important factor in the onset of deep calf vein thrombosis and pulmonary embolism. It is concluded that cancer represents an increased risk factor for onset of pulmonary embolism, in particular in patients with ovarian cancer and cancer of the extrahepatic bile duct system.

Ever since the classic work of Trousseau was published' it has been known that malignant neoplasms increase the risk of thrombosis. Certain cancers are known to possess a special propensity for thrombo-embolism. Among these are pancreatic and gastrointestinal cancers. ${ }^{23}$ On the other hand, thrombo-embolism in untreated cancer of the prostate gland and the skin is extremely rare. ${ }^{3}$ There are many reports on thrombosis and cancer ${ }^{2-7}$ but few recent comprehensive reports dealing specifically with pulmonary embolism and cancer. ${ }^{8}$ The present study was undertaken to rectify this and to elucidate the prevalence of pulmonary embolism in different primary cancer types and sites. Whether pulmonary embolism had increased or decreased among cancer patients over the 25 years studied was also investigated.

The study comprises all cases with cancer coming to necropsy at this department between 1960 and 1984 . Special attention was paid to patients treated palliatively for the last six months before they died from or with cancer to study the possible effect of cancer type on the onset of pulmonary embolism.

\section{Material and methods}

All patients with cancer were selected from our necropsy records between 1960-1984. These records

Accepted for publication 6 April 1989 have been described in detail previously. ${ }^{9}$ Altogether, 21530 hospital necropsies were carried out in this department during this period. Among these, 6197 patients had a malignant neoplasm. In 5514 cases cancer was the underlying cause of death. The annual rate of necropsies was between $75-80 \%$ of all deaths in the hospital during the whole period. Hospital admissions came from the same area with few changes in the population.

The following data from all cancer patients were compiled: necropsy registration number, type of treatment, department in which the patient died, age, month of death, presence or absence of pulmonary embolism, whether pulmonary embolism had been clinically diagnosed, basic cause of death, immediate cause of death, up to two diagnoses contributing to death or incidental findings, and days in hospital during last admission.

Almost all pulmonary emboli in this series were macroscopical findings. The prevalence of pulmonary embolism was estimated according to type and site of the cancer and the organ system from which the cancer had arisen. Patients treated palliatively for the last six months before death were given particular attention. This selection was made to avoid the immediate effects on thrombogenesis of surgery, radiation treatment, or chemotherapy. The codes from the International Classification of Diseases were used.

The $\chi^{2}$ test with one degree of freedom was used for statistical analysis. 
Table 1 Association between pulmonary embolism and cancer in necropsy cases 1960-1984

\begin{tabular}{llll}
\hline & $\begin{array}{l}\text { All } \\
(\%)\end{array}$ & $\begin{array}{l}\text { Cancer as } \\
\text { contributory } \\
\text { cause }(\%)\end{array}$ & $\begin{array}{l}\text { Cancer as } \\
\text { underlying } \\
\text { cause }(\%)\end{array}$ \\
\hline Palliatively treated & $349 / 3199$ & $67 / 572$ & $282 / 2627$ \\
& $(10.9)$ & $(11.7)$ & $(10.7)$ \\
Radically treated & $299 / 2998$ & $12 / 111$ & $287 / 2887$ \\
& $(10.0)$ & $(10.8)$ & $(9.9)$ \\
Total & $648 / 6197$ & $79 / 683$ & $569 / 5514$ \\
Non-neoplastic diseases & $(10.5)$ & $(11.6)$ & $(10.3)$ \\
& $1286 / 15333$ & \\
\hline
\end{tabular}

Cancer $v$ non-neoplastic diseases $\chi^{2}=19 \cdot 16, \mathrm{p}<0.0005$.

\section{Results}

A striking finding was that 648 of $6197(10 \cdot 5 \%)$ of patients who died of or with cancer had pulmonary embolism, whereas pulmonary embolism was found in only 1286 of $15333(8.4 \%)$ of patients dying of other causes. This difference was significant whether the patients had been radically or palliatively treated (table 1). No significant difference was found among patients with cancer as the underlying cause of death, as an incidental finding, or as a contributory cause of death. In the latter cases the underlying cause of death was mainly cardiovascular disease (table 1 ). In the cases with cancer as the underlying cause of death, cardiovascular diseases other than pulmonary embolism were found in 79 of $683(11.6 \%)$ in both those palliatively or radically treated.

Between 1960 and 1984 the prevalence of pulmonary embolism in palliatively treated patients increased up to the middle of the 1970s and decreased again towards 1984 (table 2). There was less pulmonary embolism among all palliatively treated cancer patients between 1960 and 1984 than between
Table 2 Pulmonary embolism in palliatively treated patients with cancer

\begin{tabular}{|c|c|c|c|}
\hline Years & $\begin{array}{l}A l l^{*} \\
(\%)\end{array}$ & $\begin{array}{l}\text { Cancer as } \\
\text { cause of } \ddagger \\
\text { death } \\
(\%)\end{array}$ & $\begin{array}{l}\text { Cancer as } \\
\text { contributory } 1 \\
\text { cause } \\
(\%)\end{array}$ \\
\hline $1960-64$ & $\begin{array}{c}28 / 424 \\
(6 \cdot 6)\end{array}$ & $\begin{array}{c}23 / 362 \\
(6 \cdot 3)\end{array}$ & $\begin{array}{l}5 / 62 \\
(8 \cdot 1)\end{array}$ \\
\hline $1965-69$ & $\begin{array}{l}66 / 643 \\
(10 \cdot 3)\end{array}$ & $\begin{array}{l}56 / 549 \\
(10 \cdot 2)\end{array}$ & $\begin{array}{l}10 / 94 \\
(10 \cdot 6)\end{array}$ \\
\hline $1970-74$ & $\begin{array}{l}91 / 612 \\
(14.9)\end{array}$ & $\begin{array}{l}74 / 493 \\
(15.0)\end{array}$ & $\begin{array}{l}17 / 119 \\
(14 \cdot 3)\end{array}$ \\
\hline $1975-79$ & $\begin{array}{l}71 / 660 \\
(10 \cdot 8)\end{array}$ & $\begin{array}{l}56 / 492 \\
(11.4)\end{array}$ & $\begin{array}{c}15 / 168 \\
(8.9)\end{array}$ \\
\hline $1980-84$ & $\begin{array}{l}93 / 860 \\
(11 \cdot 2)\end{array}$ & $\begin{array}{l}73 / 731 \\
(10.0)\end{array}$ & $\begin{array}{l}20 / 129 \\
(15 \cdot 5)\end{array}$ \\
\hline
\end{tabular}

*1960-64v1980-84 $\chi^{2}=4.95, \mathrm{p}<0.025$

$+1960-64 v 1970-74 \chi^{2}=12.55, \mathrm{p}<0.0005$

$\$ 1970-74 v 1980-84 \quad \chi^{2}=5.48, \mathrm{p}<0.025$

$\$ 1960-64 v 1980-84 \quad \chi^{2}=3 \cdot 38$, NS.

1980 and 1984. The same trend was observed in patients with cancer as the underlying cause of death. (Table 2).

Table 3 shows the prevalence of pulmonary embolism among palliatively treated cancer patients grouped according to the origin of the cancer and organ system. Patients with intra-abdominal and pelvic cancers had the highest rate of pulmonary embolism as did those women with cancers of the reproductive system compared with those of the respiratory system. No significant differences were seen, however, between cancers of the reproductive system and those of the hepatobiliary-pancreatic system or gastrointestinal tract $(p<0.025)$. The lowest prevalences were seen in haematological cancers. Those arising in organs of the peritoneal cavity have a significantly higher association with pulmonary embolism than all other cancers combined $\left(\chi^{2}=22.91\right.$; $\mathrm{p}<0.0005$ ).

Table 3 Association between pulmonary embolism and palliatively treated cancers according to site or organ system

\begin{tabular}{|c|c|c|c|c|}
\hline & & $\begin{array}{l}\text { Pulmonary } \\
\text { embolism }\end{array}$ & $\begin{array}{l}\text { Palli } \\
\text { treat }\end{array}$ & $\%$ \\
\hline $\begin{array}{l}1 \\
2 \\
3 \\
4 \\
5\end{array}$ & $\begin{array}{l}\text { Intra-abdominal cancers } 047,048,155,157,189 \\
\text { Cancer of pelvis } 049,055,056,057,183,188 \\
\text { Intrathoracal cancers } 046,050,051 \\
\text { Cancers of head and neck 050,191, } 193 \\
\text { Cancers } 053,054\end{array}$ & $\begin{array}{r}129 \\
49 \\
49 \\
17 \\
18\end{array}$ & $\begin{array}{l}871 \\
423 \\
515 \\
180 \\
226\end{array}$ & $\begin{array}{r}14 \cdot 8 \\
11 \cdot 6 \\
9 \cdot 5 \\
9 \cdot 4 \\
8 \cdot 0\end{array}$ \\
\hline $\begin{array}{r}6 \\
7 \\
8 \\
9 \\
10 \\
11\end{array}$ & $\begin{array}{l}\text { Organ system } \\
\text { Female reproductive system } 055,056,183 \\
\text { Hepato-biliary pancreatic system } 155,156,157 \\
\text { Gastrointestinal tract } 046,047,048,049 \\
\text { Respiratory system } 050,051 \\
\text { Urogenital system } 057,188,189 \\
\text { Haematological and lymphatic systems } 059,060\end{array}$ & $\begin{array}{l}28 \\
46 \\
78 \\
49 \\
26 \\
13\end{array}$ & $\begin{array}{l}152 \\
296 \\
592 \\
488 \\
281 \\
253\end{array}$ & $\begin{array}{r}18 \cdot 4 \\
15 \cdot 5 \\
13 \cdot 2 \\
10 \cdot 0 \\
9 \cdot 3 \\
5 \cdot 1\end{array}$ \\
\hline
\end{tabular}

1 v 3: $\chi^{2}=6.34, \mathrm{p}<0.025$

6 v 9: $\chi^{2}=5.82, \mathrm{p}<0.025$ 
Table 4 Pulmonary embolism associated with different cancers and prevalence of cardiovascular disease in palliatively treated patients

\begin{tabular}{|c|c|c|c|c|}
\hline & $\begin{array}{l}\text { Cancer } \\
\text { type (ICD) }\end{array}$ & $\begin{array}{l}\text { No of palliatively } \\
\text { treated patients }\end{array}$ & $\begin{array}{l}\text { Percentage with } \\
\text { pulmonary embolism }\end{array}$ & $\begin{array}{l}\text { Hospital stay (range), age (range), } \\
\text { and cardiovascular disease }\end{array}$ \\
\hline $\begin{array}{l}1 \\
2 \\
3 \\
4 \\
5 \\
6 \\
7\end{array}$ & $\begin{array}{l}\text { Ovary (183) } \\
\text { Extrahepatic bile duct system (156) } \\
\text { Stomach (047) } \\
\text { Large bowel (048) } \\
\text { Pancreas (157) } \\
\text { Uterine body (056) } \\
\text { Brain (191) }\end{array}$ & $\begin{array}{r}55 \\
41 \\
316 \\
169 \\
199 \\
41 \\
134\end{array}$ & $\begin{array}{l}(34 \cdot 5) \\
(31 \cdot 7) \\
(15 \cdot 2) \\
(14 \cdot 8) \\
(14 \cdot 6) \\
(12 \cdot 2) \\
(11 \cdot 2)\end{array}$ & $14(1-365), 70(1-95),(13 \cdot 2 \%)$ \\
\hline $\begin{array}{r}8 \\
9 \\
10 \\
11 \\
12 \\
13 \\
14\end{array}$ & $\begin{array}{l}\text { Kidney (189) } \\
\text { Lung (051) } \\
\text { Prostate gland (057) } \\
\text { Skin (053) } \\
\text { Female breast (054) } \\
\text { Uterine cervix (055) } \\
\text { Liver (155) }\end{array}$ & $\begin{array}{r}90 \\
478 \\
120 \\
50 \\
176 \\
56 \\
56\end{array}$ & $\begin{array}{r}(11 \cdot 1) \\
(10 \cdot 3) \\
(10 \cdot 0) \\
(8 \cdot 0) \\
(8 \cdot 0) \\
(7 \cdot 1) \\
(7 \cdot 1)\end{array}$ & $15(1-365), 68(1-94),(13 \cdot 1 \%)$ \\
\hline $\begin{array}{l}15 \\
16 \\
17 \\
18 \\
19 \\
20 \\
21\end{array}$ & $\begin{array}{l}\text { Rectum }(049) \\
\text { Thyroid gland (193) } \\
\text { Urinary bladder (188) } \\
\text { Myelomatosis, lymphoma (060) } \\
\text { Leukaemia (059) } \\
\text { Larynx (050) } \\
\text { Oesophagus (046) }\end{array}$ & $\begin{array}{r}80 \\
35 \\
71 \\
126 \\
127 \\
11 \\
27\end{array}$ & $\begin{array}{l}(6 \cdot 3) \\
(5 \cdot 7) \\
(5 \cdot 6) \\
(5 \cdot 6) \\
(4 \cdot 7) \\
(0 \cdot 0) \\
(0 \cdot 0)\end{array}$ & $13(1-365), 70(1-94),(13 \cdot 2 \%)$ \\
\hline
\end{tabular}

Cancer of ovary $v$ stomach $\chi^{2}=7.40, p<0.01$

Among palliatively treated malignant neoplasms, cancer of the ovary showed the highest prevalence of pulmonary embolism (table 4). This cancer, together with cancer of the extrahepatic bile duct system, showed a significantly higher prevalence of pulmonary embolism than all other cancers. Adenocarcinomas, and cancer of the stomach, large bowel, and pancreas also had a similarly high prevalence of pulmonary embolism. The lowest prevalence was seen among leukaemias, cancer of the larynx, and oesophagus. In the last two no pulmonary embolism was observed but the numbers were small (table 4). Neither stay in hospital nor age seemed to differ significantly among cancer patients at high or low risk of pulmonary embolism (table 4). Furthermore, there was no difference in the prevalence of cardiovascular diseases among the seven cancers with the highest rate of pulmonary embolism compared with the seven $(13 \%)$ cancers with the lowest.

As far as the number of days in hospital and age were concerned (table 5), there were no significant differences between those patients with and without pulmonary embolism.

Table 5 Median stay in hospital during last admission and median age among cancer patients with and without pulmonary embolism

\begin{tabular}{llll}
\hline $\begin{array}{l}\text { Palliatively } \\
\text { treated patients }\end{array} \quad(n=)$ & $\begin{array}{l}\text { Hospital stay } \\
\text { (range) }\end{array}$ & $\begin{array}{l}\text { Age } \\
\text { (range) }\end{array}$ \\
\hline $\begin{array}{l}\text { With pulmonary } \\
\text { embolism }\end{array}$ & 282 & $15(1-365)$ & $70(14-95)$ \\
$\begin{array}{l}\text { Without pulmonary } \\
\text { embolism }\end{array} 2345$ & $14(1-365)$ & $69(1-95)$ \\
\hline
\end{tabular}

\section{Discussion}

Pulmonary embolism is often extremely difficult to diagnose clinically and studies on the prevalence of this serious disease have to be based on necropsy material. ${ }^{1011}$ This overview has shown that cancer patients have an increased risk of pulmonary embolism compared with patients with other diseases. Most of the latter are cardiovascular diseases. Our findings seem to contradict those of Berger and Freudenberg, who found no difference in pulmonary embolism between cancer patients and those with cardiovascular diseases. ${ }^{8}$

An increase in thrombosis among patients with malignant tumours has been indicated ever since Trousseau diew attention to the association between cancer and thrombosis. Malignant tumours influence several factors which promote thrombosis. Many reports have shown that thrombocytosis is associated with malignant disease ${ }^{12-16}$; others point to changes in coagulation. ${ }^{367}$ Thrombophlebitis of the lower limb has been linked with malignant disease. ${ }^{4}$ Deep calf vein thrombosis is the main source of pulmonary embolism ${ }^{11}$ and the incidence of pulmonary embolism probably reflects the prevalence of thrombosis in a large series like the one reported here. This is supported by the fact that pancreatic cancer and cancer of the stomach are both commonly associated with a high rate of thrombosis. ${ }^{31718}$ These cancers were among those with the highest prevalence of pulmonary embolism in this study. Deep vein thrombosis is not routinely investigated in our hospital necropsies. Most macroscopical pulmonary emboli are, however, 
probably detected because the pulmonary arteries are opened carefully at necropsy.

This study has shown that cancers arising in organs of the peritoneal cavity, in particular, ovarian and extrahepatic bile duct cancers, are especially liable to promote pulmonary embolism. Cancers in this location may affect flow in the inferior cava vein and promote stasis in the lower limbs. Thus mechanical dysfunction may be of clinical importance. As the extent of the metastatic process in the cancers studied was not assessed we cannot tell whether metastases to the peritoneal cavity from cancers in other sites also promote pulmonary embolism.

Why is the prevalence of pulmonary embolism so high in patients with cancer of the ovary? A high rate of thrombophlebitis has been reported in patients with cancer of the reproductive system, ${ }^{4}$ possibly due to obstruction caused by the tumour mass in the pelvis. ${ }^{17}$ Ovarian cancers may also produce oestrogen 19 and oestrogen can affect coagulation. ${ }^{20}$ Treatment with oestrogens in cancer of the prostate has led to increased risk of thrombosis, ${ }^{4}$ but ovarian cancer often produces peritoneal seeding with ascites which may exacerbate stasis in the deep calf veins during bedrest.

Extrahepatic bile duct cancer, also an intraperitoneal cancer, is well known for its extensive fibrosis. ${ }^{21}$ This could interfere with venous drainage through the inferior cava vein and thus promote deep calf vein thrombosis and pulmonary embolism. A similar mechanism may be implicated in patients with cancer of the gastrointestinal tract. These cancers also produce mucus, however, which may affect coagulation. ${ }^{2223}$

The risk of pulmonary embolism among patients with ovarian and bile duct cancer is very high. The question arises as to whether anticoagulants or platelet inhibiting drugs should be given prophylactically to these and other cancer patients at high risk. Anticoagulation may in fact also impede metastasis. ${ }^{234}$ Cancer patients, however, have been reported to be resistant to anticoagulant treatment ${ }^{425}$ and more data on the potential benefits of this treatment are required.

Patients with leukaemia and hepatoma had a low prevalence of pulmonary embolism. The explanation for this could be that bone marrow is destroyed by thrombocytopenia in leukaemia and that coagulation is reduced in hepatoma. Metastasis to the liver, however, may decrease the risk of pulmonary embolism. Mason et al reported that patients with untreated chronic granulocytic leukaemia have a high prevalence of thrombocytosis and a shorter survival than patients with normal platelet counts. ${ }^{12}$

From the early 1960 s to the middle 1970 s there was a rise in the number of cases of pulmonary embolism in our palliatively treated cancer patients, with a decline towards the middle 1980s. We have no explanation for this. Other reports have shown no increase in the incidence of pulmonary embolism, although thrombolitic disease as a whole increased. ${ }^{8}$

The prevalence of pulmonary embolism varies among patients with different types of cancers. This is not explained by significant differences in cardiovascular diseases among cancer patients, or by bedrest. Although the number of days of bedrest was not estimated, there was no significant difference in the duration of the final admission. In the terminal stage this probably reflects bed rest immediately before death and comparison between different cancer patients is therefore justified. As has been shown previously, old age is a significant factor for pulmonary embolism." Pulmonary embolism was seen only very rarely among younger patients, the youngest being 14 years old. Below 40 years, only seven $(1.7 \%)$ cancer patients had pulmonary embolism. The fact that the length of stay in hospital during last admission and the age of palliatively treated cancer patients with pulmonary embolism were not greater than those without reinforces the assumption that type and site of cancer influence the risk of pulmonary embolism.

We thank Professor Hartveit for helpful advice and Ms Linda Forshaw for typing the manuscript.

\section{References}

1 Trousseau A. Phlegmasia alba dolens. Clinique medicale de l'Hotel-Dieu Paris-London. The New Sydenham Society 1865;3:94.

2 Edwards RL, Rickles FR. Hemostatic alterations in cancer patients. In Honn KV, Sloane BF, eds. Hemostatic mechanisms and metastasis. Boston: Martinus Niijhoff, 1984:343-54.

3 Dvorak HF. Thrombosis and cancer. Hum Pathol 1974;18:275-84.

4 Lieberman JS, Borrero J, Urdaneta E, Wright IS. Thrombophlebitis and cancer. JAMA 1961;177:542-5.

5 Sun NCJ, McFee WM, Hum GI, Weiner JM. Hemostatic abnormalities in malignancy, a prospective study of one hundred and eight patients. Am J Clin Pathol 1979;71:10-6.

6 Sack GH, Levin J, Bell W. Trousseau's syndrom and other manifestations of chronic disseminated coagulopathy in patients with neoplasms: Clinical, pathophysiologic, and therapeutic features. Medicine 1977;56:1-37.

7 Pineo GF, Brain HC, Gallus AS, Hirsh J, Halton MWC, Ragoezi E. Tumors, mucus production, and hypercoagulability. Am NY Acad Sci 1974;230:262-70.

8 Berger H, Freudenberg N. Todesursachen bei Malignompatienten. Med Welt 1983;34:112-8.

9 Hartveit F. Autopsy findings in cases with clinically uncertain cancer diagnosis. J Pathol 1979;129:111-9.

10 Karwinski B, Svendsen E. Comparison of clinical and postmortem diagnosis of pulmonary embolism. J Clin Pathol 1989;42:135-9.

11 Havig $\varnothing$. Deep vein thrombosis and pulmonary embolism. An autopsy study with multiple regression analysis of possible risk factors. Acta Chir Scand 1977;suppl 478:24-76.

12 Mason JE, DeVita VT, Canellos GP. Thrombocytosis in chronic granulocytic leukemia: Incidence and clinical significance. Blood 1974;44:483-7. 
13 Silvis SE, Turkbas N, Dorscherholmen A. Thrombocytosis in patients with lung cancer. JAMA 1970;211:1852-3.

14 Mayr AC, Dick GA, Sean HJ. Thrombozytose bei malignen Tumoren. Schweiz Med Wochenschr 1973;103:1626-9.

15 Spigel SC, Mooney LR. Extreme thrombocytosis associated with malignancy. Cancer 1977;39:339-41.

16 Schneider W. Tumor, Thrombozytose und Thrombosegefährung. Disch Med Wochenschr 1988;113:740-6.

17 Sproule EE. Carcinoma and venous thrombosis: The frequency of association of carcinoma in the body or tail of the pancreas with multiple venous thrombosis. Am J Cancer 1938;34:566-85.

18 Thomsen CM, Rodgers LR. Analysis of the autopsy of 157 cases of carcinoma of the pancreas with particular reference to the incidence of thromboembolism. Am J Med Sci 1952;223: 469-75.

19 Mählck C-G, Bäckström T, Kjellgren O. Plasma level of estradiol in patients with malignant tumors. Gynecol Oncol 1988; 30:313-20.

20 Poller L. Oral contraceptives, blood clotting and thrombosis. $\mathrm{Br}$ Med Bull 1978;34:151-6.
21 Edmondson HA. Atlas of Tumor Pathology. Section VII, Fascicle 26. Tumors of the gallbladder and extrahepatic bile ducts. Armed Forces Institute of Pathology, Washington, DC, 1967:91-120.

22 Brain MC, Azzopardi JG, Baker LRI, Pineo GF, Roberts PD, Dacie JV. Microangiopathic haemolytic anaemia and mucinforming adenocarcinoma. Br J Haematol 1970;18:183-93.

23 Belt RJ, Leite $C$, Haas CD, Stephens RL. Incidence of hemorrhagic complications in patients with cancer. JAMA 1978;239:2571-4.

24 Kohanna FH, Sweeney J, Hussey S, Zacharski LR, Salzman EW. Effect of perioperative low-dose heparin administration on the course of colon cancer. Surgery 1983;93:433-8.

25 Wright IS, George E. Brown Memorial Lecture: Pathogenesis and Treatment of Thrombosis. Circulation 1952;5:161-88.

Requests for reprints to: Dr Einar Svendsen, Department of Pathology, The Gade Institute, Haukeland Hospital, 5021 Bergen, Norway. 